\title{
Association between dairy consumption and ischemic heart disease among Chinese adults: a prospective study in Qingdao
}

\author{
Jiahui Song ${ }^{1}$, Chi Pan${ }^{1}$, Feifei $\mathrm{Li}^{2,3}$, Yu Guo ${ }^{4}$, Pei Pei ${ }^{4}$, Xiaocao Tiann ${ }^{2,3^{*}}$, Shaojie Wang ${ }^{2,3}$, Ruqin Gao ${ }^{2,3 *}$,
} Zengchang Pang ${ }^{2,3}$, Zhengming Chen ${ }^{5}$ and Liming Li ${ }^{6}$

\begin{abstract}
Background: Previous studies linking dairy consumption with ischemic heart disease (IHD) are almost from western countries, with little from China. The present study was to explore the relationship between dairy consumption and IHD among Chinese adults.

Methods: The data for the present study was from the prospective cohort study of China Kadoorie Biobank in Qingdao, a total of 33,355 participants in the present study. An interviewer-administered laptop-based questionnaire was used to collect information on the consumption frequency of dairy, incident IHD cases were identified through Disease Surveillance Point System and the new national health insurance databases. Cox regression analyses were performed to estimate adjusted hazard ratios (HRs) and confidence interval for the relationship between the incidence of IHD and dairy consumption.

Results: The baseline survey reported that $32.4 \%$ of males and $34.6 \%$ of females consumed dairy regularly (i.e. $\geq 4$ days/week). Over an average of 9.2 years follow-up, 2712 new-onset IHD were documented. Compared with participants who never or rarely consume dairy, the HR of consumed dairy regularly was 0.85(0.73-0.98) for males $(P<0.05)$, while no significant benefits were identified for females.
\end{abstract}

Conclusions: Regular dairy consumption had an inverse association to the onset of IHD among males, with no similar findings for females.

Keywords: China, Prospective study, Dairy, Ischemic heart disease

\section{Introduction}

IHD is the leading cause of death worldwide [1]. The number of deaths caused by IHD reached 9.14 million and the number of disability-adjusted life years (DALYs) reached 182.03 million in 2019 [2]. In 2016, the IHD mortality rate ranked first, accounting for $40 \%$ of mortality in Chinese adults [3], indicating that it has become a serious public health issue [4]. IHD-related hospitalization rates

\footnotetext{
*Correspondence: txc 2006911@126.com; gaoruqin@sohu.com

${ }^{2}$ Qingdao Municipality Center for Disease Control and Prevention, Qingdao 266033, China

Full list of author information is available at the end of the article
}

annually increased $5.4 \%$ in the China Kadoorie Biobank (CKB) cohort study [5].

Dairy contains more saturated than unsaturated fat. Previous studies linked full-fat dairy consumption with an increased risk of IHD [6]. Some studies have suggested that dairy consumption has a positive or a neutral association with cardiovascular disease and all-cause mortality [7-9]. Observational studies from western countries suggested that the intake of full-fat dairy was in a neutral or inverse association with the onset of IHD $[10,11]$. With higher consumption of butter and cheese, most Western countries' dietary guidelines recommended

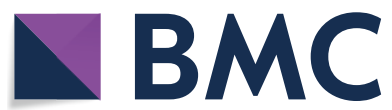

(c) The Author(s) 2022. Open Access This article is licensed under a Creative Commons Attribution 4.0 International License, which permits use, sharing, adaptation, distribution and reproduction in any medium or format, as long as you give appropriate credit to the original author(s) and the source, provide a link to the Creative Commons licence, and indicate if changes were made. The images or other third party material in this article are included in the article's Creative Commons licence, unless indicated otherwise in a credit line to the material. If material is not included in the article's Creative Commons licence and your intended use is not permitted by statutory regulation or exceeds the permitted use, you will need to obtain permission directly from the copyright holder. To view a copy of this licence, visit http://creativecommons.org/licenses/by/4.0/. The Creative Commons Public Domain Dedication waiver (http://creativeco mmons.org/publicdomain/zero/1.0/) applies to the data made available in this article, unless otherwise stated in a credit line to the data. 
the intake of low-fat milk (i.e., milk fat $<0.5 \%$ ) in place of full-fat dairy (i.e., milk fat $>3 \%$ ) [12], while the WHO recommended an intake of whole milk or dairy products (e.g., cheese) of $250 \mathrm{~g} /$ day [13]. A study including 7354 healthy adults in Korea aged 40-69 supported that those who consumed higher amounts of milk or dairy products had a protective association with the cardiovascular system [14]. Another prospective cohort study conducted in China found that, compared with no consumption, increased consumption of dairy products had a lower risk of CVD mortality. Dairy consumption in China is much lower than in Western countries [15]. Consumption of dairy products continues to be low in China, with only a slight increase over time [16].

Existing evidence on the effect of dairy consumption on IHD is still controversial and mainly comes from Western countries. The association between dairy and IHD risk has rarely been investigated among Chinese adults. The present study investigated the relationship between dairy consumption and the risk of IHD.

\section{Materials and methods \\ Study population}

The participants of the present study came from the prospective survey of the China Kadoorie Biobank (CKB) in Qingdao. Details of the study have been previously reported [17-19]. A total of 35,508 residents, aged 30-79 years (born in 1930-1970) completed the baseline survey in 2004-2008. Participants who self-reported IHD $(n=1827)$, stroke $(n=238)$, or cancer $(n=162)$ at the baseline survey were excluded, and the final analysis included 33,355 participants.

The ethics board of the University of Oxford and the National, Shandong Provincial, and Qingdao Centers for Disease Control and Prevention in China all approved this study. All of the participants in the survey signed written informed consent forms.

\section{Data collection}

The validated laptop-based questionnaire was completed by trained health workers, including sociodemographic information (age, education, occupation, household income, marital status), lifestyle (alcohol consumption, smoking status), family history, dairy products, and other diet frequency (rice, wheat, other staple foods, red meat, poultry, fish, eggs, fresh fruit, fresh vegetables, soybean, and preserved vegetables) in the last 12 months. The answer for the frequency of dairy (e.g., milk, yogurt) consumption included 5 groups (never/rarely, 1-3 d/month, 1-3 d/week, 4-6 d/week, daily). The questionnaire has good reproducibility and relative validity against multiple $24 \mathrm{~h}$ recalls (weighted $\mathrm{k}$ was 0.78 ) [20].
Physiological measurements include body weight, height, waist circumference (WC), blood pressure, random glucose, etc. Body mass index (BMI) was calculated as weight $(\mathrm{kg})$ divided by height squared $\left(\mathrm{m}^{2}\right)$. Systolic blood pressure (SBP) and diastolic blood pressure (DBP): for each individual, blood pressure was measured twice and taken as the average. A third measure was required if the blood pressure difference was more than $10 \mathrm{~mm}$ $\mathrm{Hg}$ between the first two measures, and the average of the last two blood pressure values was recorded. Random blood glucose levels were measured immediately following sample collection using the SureStep Plus System (Johnson \& Johnson, New Brunswick, NJ, USA).

\section{Follow-up for IHD and MCE}

The primary outcome was the incidence and mortality of IHD (International Classification of Diseases-10: I20I25) and MCE (major coronary event). MCE includes fatal IHD (I20-I25) and nonfatal myocardial infarction (I21-I23). This was ascertained through the Disease Surveillance Point System (DSPs) and the new national health insurance databases [21]. Participants were followed up from baseline until the date of IHD or MCE incidence or mortality, loss to follow-up, or December 31, 2015, whichever came first.

\section{Statistical analysis}

The series of characteristics of the participants were described with frequency $(\mathrm{N})$ and percentages (\%) according to categories of dairy consumption, using Student's t-test for continuous variables and the chi-square test for categorical variables.

To estimate the hazard ratios (HRs) and 95\% confidence intervals (CIs) of dairy consumption and IHD risk, a Cox proportional hazards model was applied. The proportional hazards assumption for the Cox model was examined by testing the significance level of the interaction terms between dairy consumption and time. Potential confounding factors were adjusted in the different models. In Model 1, hazard ratios were adjusted for age (continuous variable) and sex (male or female); Model 2 was additionally adjusted for education (below high school, high school and above), occupation, marital status, household income $(<20,000$ yuan or $\geq 20,000$ yuan), diet frequency (egg, fresh vegetables, red meat, fresh fruit, poultry, soybean), smoking status (noncurrent smoking or current smoking), alcohol consumption (noncurrent drinking or current drinking), and metabolic equivalent of task (MET); Model 3 was additionally adjusted for BMI (continuous variable), SBP (continuous variable), $\mathrm{DBP}$ (continuous variable), random glucose (continuous variable), and family history of myocardial infarction (MI). 
Subgroup analysis was performed to investigate the relationship between dairy consumption and the risk of IHD, according to baseline characteristics, including age ( $\leq 50 \mathrm{y}$ or $>50 \mathrm{y}$ ), education (below high school, or high school and above), occupation (yes or no), marital status (yes or no), household income $(<20,000$ yuan or $\geq 20,000$ yuan), smoking status (noncurrent smoking or current smoking), alcohol consumption (noncurrent drinking or current drinking), MET $(\leq 15 \mathrm{~h} / \mathrm{d}$ or $>15 \mathrm{~h} / \mathrm{d})$, BMI $\left(<24 \mathrm{~kg} / \mathrm{m}^{2}, 24-28 \mathrm{~kg} / \mathrm{m}^{2}\right.$, and $\geq 28 \mathrm{~kg} /$ $\left.\mathrm{m}^{2}\right)$, SBP $(<140 \mathrm{mmHg}$ or $\geq 140 \mathrm{mmHg})$, random glucose $(<11.1 \mathrm{mmol} / \mathrm{L}$ or $\geq 11.1 \mathrm{mmol} / \mathrm{L})$, and family history (yes or no). The significance of the interaction was examined by the likelihood ratio test, comparing models with and without interaction terms between the stratifying variable and dairy consumption.

All $P$ values were two-sided, and $P<0.05$ was considered to be statistically significant. All analyses were performed using SPSS (version 25.0). All graphs were plotted using R 4.0.5 (https://www.R-project.org/).

\section{Results:}

\section{Characteristics of the participants}

Among the 33,355 participants, the mean (SD) age at baseline was 50.7 (10.0) years. A total of $32.4 \%$ of male and $34.6 \%$ of female participants consumed dairy daily (Table 1). Participants who consumed dairy more frequently were more likely to be female, and have a higher education level, a higher MET, lower blood pressure and lower BMI $(P<0.05)$ (Additional file 1: Table S1).

\section{Association between dairy consumption and IHD}

During an average of 9.2 years of follow-up (305,655.5 person-years), a total of 2712 incident IHD cases $(1,075$ men and 1637 women) and 420 incident MCE cases (271 men and 149 women) were documented (dditional file 1: Table S2), with an incidence of 887.3 (713.8 for men, and 892.0 for women) per 100,000 person-years. The multivariable Cox proportional hazards model was used to analyze the relationship between dairy consumption and the onset of IHD. After adjusting for major covariates,

Table 1 Baseline characteristics of participants by frequency of dairy consumption

\begin{tabular}{|c|c|c|c|c|c|c|}
\hline \multirow[t]{2}{*}{ Characteristics } & \multicolumn{5}{|c|}{ Dairy consumption } & \multirow[t]{2}{*}{ Overall } \\
\hline & Never & Monthly & 1-3 day/week & 4-6 day/week & Daily & \\
\hline Number of participants & 10,395 & 3555 & 6757 & 1446 & 11,202 & 33,355 \\
\hline Women (\%) & 55.6 & 52.3 & 53.7 & 56.6 & 56.8 & 55.3 \\
\hline Mean age (years) & $51.8(9.6)$ & $51.2(10.0)$ & $49.5(9.6)$ & $47.7(9.8)$ & $50.6(10.5)$ & $50.7(10.0)$ \\
\hline High school and above (\%) & 26.1 & 35.8 & 41.2 & 49.8 & 41.6 & 36.4 \\
\hline Factory/Professional/sales (\%) & 50.4 & 55.4 & 61.2 & 69.8 & 58.7 & 56.7 \\
\hline Married (\%) & 92.0 & 92.5 & 94.6 & 94.9 & 92.7 & 92.9 \\
\hline Household income $\geq 20,000$ (yuan) (\%) & 51.6 & 62.1 & 67.4 & 70.2 & 63.8 & 60.8 \\
\hline \multicolumn{7}{|l|}{ Regular food consumption $^{\mathrm{a}}(\%)$} \\
\hline Eggs & 47.5 & 43.2 & 41.2 & 40.0 & 66.0 & 51.7 \\
\hline Fresh fruit & 47.5 & 41.3 & 50.4 & 50.1 & 67.3 & 54.2 \\
\hline Fresh vegetables & 98.8 & 98.0 & 96.5 & 94.9 & 98.9 & 98.1 \\
\hline Soybean & 6.8 & 4.9 & 4.6 & 6.4 & 9.9 & 7.2 \\
\hline Red meat & 61.0 & 62.0 & 54.0 & 53.8 & 68.5 & 61.9 \\
\hline Poultry & 1.3 & 1.7 & 3.9 & 2.1 & 1.9 & 2.1 \\
\hline Current drinking in men ${ }^{\mathrm{b}}(\%)$ & 53.7 & 45.4 & 43.7 & 47.0 & 48.8 & 48.8 \\
\hline Current smoking in men ${ }^{\mathrm{b}}(\%)$ & 65.6 & 58.6 & 54.2 & 54.1 & 57.2 & 59.2 \\
\hline MET (MET-hr/day) & $15.2(10.1)$ & $15.4(10.6)$ & $17.0(10.9)$ & $19.9(11.4)$ & $17.6(10.1)$ & $16.6(10.4)$ \\
\hline $\mathrm{BMI}\left(\mathrm{Kg} / \mathrm{m}^{2}\right)$ & $26.3(3.7)$ & $25.9(3.7)$ & $25.5(3.4)$ & $25.0(3.4)$ & $25.4(3.6)$ & $25.7(3.6)$ \\
\hline $\mathrm{SBP}(\mathrm{mmHg})$ & $132.3(22.5)$ & $130.4(21.5)$ & $128.9(21.5)$ & $126.3(19.8)$ & $128.2(20.9)$ & $129.7(21.6)$ \\
\hline $\mathrm{DBP}(\mathrm{mmHg})$ & $78.9(10.9)$ & $77.8(11.1)$ & 77.6(10.8) & $76.5(10.5)$ & $77.6(10.5)$ & $77.6(10.8)$ \\
\hline Random glucose ${ }^{c}(\mathrm{mmol} / \mathrm{L})$ & $6.4(2.4)$ & $6.4(2.9)$ & $6.2(2.4)$ & $6.0(2.1)$ & $6.4(2.8)$ & $6.3(2.6)$ \\
\hline Family history of MI (\%) & 5.2 & 5.0 & 4.7 & 5.5 & 6.5 & 5.5 \\
\hline
\end{tabular}

MET: exercise metabolic equivalent; BMI: Body Mass Index; SBP: Systolic Blood Pressure; DBP: Diastolic Blood Pressure; MI: myocardial infarction; Values are either percentage or mean (SD)

${ }^{\text {a }}$ Regular food consumption means consuming food products daily

${ }^{\mathrm{b}}$ In women, only $1.5 \%$ current drinking and $1.0 \%$ current smoking

c 422 participants had missing values for random glucose 
compared with participants who never or rarely consumed dairy, higher dairy intake had a neutral effect on the incidence and mortality of IHD and MCE (Table 2, 3, and dditional file 1: Table S3). The inverse association was stronger in men than in women, and no statistically significant association was found between dairy consumption and IHD in women.

For men, dairy consumption $<4$ days/week was inversely associated with the risk of IHD with an HR (95\% CI) of $0.85(0.73-1.00)$ and 0.85 (0.73-0.98) for dairy consumption $\geq 4$ days/week (Model 2). Additionally adjusted for BMI, blood pressure, and random glucose, HR was attenuated to $0.84(0.72-0.99)$ and $0.86(0.75-$ 0.99), respectively (Model 3).

\section{Subgroup analyses}

Subgroup analysis was performed to investigate the relationship between dairy consumption and the risk

Table 2 Risk of IHD, MCE and IHD mortality associated with consumption of dairy

\begin{tabular}{|c|c|c|c|}
\hline \multirow[t]{2}{*}{ Characteristics } & \multicolumn{3}{|c|}{ Dairy consumption } \\
\hline & Never & $<4$ day/week & $\geq 4$ day/ week \\
\hline \multicolumn{4}{|l|}{ IHD } \\
\hline Cases & 903 & 734 & 1075 \\
\hline PYS & $92,292.98$ & $88,778.41$ & $114,812.61$ \\
\hline Cases/PYs $(/ 100,000)$ & 978.41 & 826.78 & 936.31 \\
\hline Modle1 & 1.00 & $0.98(0.89-1.08)$ & $0.93(0.85-1.01)$ \\
\hline Modle2 & 1.00 & $0.97(0.88-1.07)$ & $0.95(0.87-1.04)$ \\
\hline Modle3 & 1.00 & $0.97(0.88-1.08)$ & $0.99(0.90-1.09)$ \\
\hline \multicolumn{4}{|l|}{ MCE } \\
\hline Cases & 142 & 108 & 170 \\
\hline PYs & $95,075.64$ & $90,932.75$ & $118,238.13$ \\
\hline Cases/PYs $(/ 100,000)$ & 149.35 & 118.77 & 143.78 \\
\hline Modle1 & 1.00 & $0.90(0.70-1.16)$ & $0.89(0.70-1.11)$ \\
\hline Modle2 & 1.00 & $0.90(0.70-1.17)$ & $0.89(0.71-1.12)$ \\
\hline Modle3 & 1.00 & $0.92(0.71-1.19)$ & $0.94(0.74-1.18)$ \\
\hline \multicolumn{4}{|l|}{ IHD mortality } \\
\hline Cases & 89 & 73 & 100 \\
\hline PYs & $95,513.82$ & $91,318.09$ & $118,823.54$ \\
\hline Cases/PYs $(/ 100,000)$ & 93.18 & 79.94 & 84.16 \\
\hline Modle1 & 1.00 & $1.04(0.76-1.42)$ & $0.80(0.60-1.06)$ \\
\hline Modle2 & 1.00 & $1.08(0.79-1.49)$ & $0.84(0.63-1.13)$ \\
\hline Modle3 & 1.00 & $1.08(0.78-1.48)$ & $0.86(0.64-1.16)$ \\
\hline
\end{tabular}

For further statistical analysis, individuals of dairy product consumption were combined into three groups (never/rarely, $<4$ days/week, $\geq 4$ days/week) Model 1: stratified by age-at-risk, gender (only in total population)

Model 2: as for model 1, additionally adjusted for education, occupation, marital status, household income, and food consumption (eggs, fresh fruit, fresh vegetables, soybean, red meat, poultry), alcohol consumption, smoking status, MET, family history of MI

Model 3: as for model 2, additionally adjusted for BMI, SBP, DBP, random glucose
Table 3 Risk of IHD associated with dairy among 14,908 male and 18,447 female participants

\begin{tabular}{llll}
\hline Characteristics & \multicolumn{2}{l}{ Dairy consumption } \\
\cline { 2 - 4 } & Never & $\mathbf{4}$ day/week & $\geq \mathbf{4}$ day/ week \\
\hline Male & 359 & 280 & \\
Cases & 1.00 & $0.88(0.75-1.02)$ & $0.87(0.75-1.00)$ \\
Modle1 & 1.00 & $0.85(0.73-1.00)$ & $0.85(0.73-0.98)$ \\
Modle2 & 1.00 & $0.84(0.72-0.99)$ & $0.86(0.75-0.99)$ \\
Modle3 & & & \\
Female & 544 & 454 & 639 \\
Cases & 1.00 & $1.05(0.93-1.19)$ & $0.97(0.86-1.08)$ \\
Modle1 & 1.00 & $1.07(0.94-1.21)$ & $1.04(0.93-1.18)$ \\
Modle2 & 1.00 & $1.08(0.95-1.23)$ & $1.10(0.97-1.24)$ \\
Modle3 & &
\end{tabular}

For further statistical analysis, individuals of dairy product consumption were combined into three groups (never/rarely, $<4$ days/week, $\geq 4$ days/week)

Model 1: stratified by age-at-risk, gender (only in total population)

Model 2: as for model 1, additionally adjusted for education, occupation, marital status, household income, and food consumption (eggs, fresh fruit, fresh vegetables, soybean, red meat, poultry), alcohol consumption, smoking status, MET, family history of MI

Model 3: as for model 2, additionally adjusted for BMI, SBP, DBP, random glucose

of IHD, according to baseline characteristics (Fig. 1). The association between dairy and IHD differed by education level $\left(P_{\text {interaction }}\right.$ : 0.017 for men and 0.014 for women) and household income ( $P_{\text {interaction }}$ : 0.048 for men and 0.032 for women). The inverse associations were more pronounced in men who had a high education level (HR 0.67, 95\% CI 0.52-0.86) than men who had a lower education level (HR 0.89, 95\% CI 0.731.08) ( $\left.P_{\text {interaction }}: 0.017\right)$ and were more pronounced in men who had a household income $\geq 20,000$ (HR 0.74, 95\% CI 0.62-0.90) than men who had a household income $<20,000$ (HR 1.04, 95\% CI 0.83-1.30) $\left(P_{\text {interaction: }}\right.$ : $0.048)$.

However, a strong positive association was observed among women with a lower level of education (HR 1.30, 95\% CI 1.15-1.48) compared to women with a higher level of education (HR 0.85, 95\% CI 0.62-1.16) $\left(P_{\text {interac- }}\right.$ tion: 0.014$)$ and was more pronounced in women whose household income was $<20,000$ (HR 1.24, 95\% CI 1.061.46) than women whose household income was $\geq 20,000$ (HR 0.95, 95\% CI 0.80-1.14) ( $P_{\text {interaction: }}$ 0.032).

Stronger inverse associations were also observed among men who had noncurrent smoking (HR 0.73, 95\% CI 0.58-0.91) than men who had current smoking (HR 0.96, 95\% CI 0.79-1.16) ( $P_{\text {interaction: }}$ 0.036). No similar associations were observed across subgroups stratified according to age, occupation, marital status, alcohol consumption, MET, BMI, SBP or family history of MI $\left(P_{\text {interaction }}>0.05\right)$. 


\begin{tabular}{|c|c|c|c|c|c|c|}
\hline $\begin{array}{l}\text { Subgroup } \\
\text { Age, (vears) }\end{array}$ & Male & $\mathrm{HR}(95 \% \mathrm{Cl})$ & P for interaction & Female & $\mathrm{HR}(95 \% \mathrm{Cl})$ & P for interaction \\
\hline $\begin{array}{l}\leq 50 \\
>50\end{array}$ & $\because$ & $\begin{array}{l}0.77(0.57,1.04) \\
0.94(080,111)\end{array}$ & & & $1.01(0.75,1.36)$ & \\
\hline Education & & $0.94(0.00,1.17)$ & 0.017 & & $1.16(1.02,1.32)$ & 0.014 \\
\hline $\begin{array}{l}\text { Below high school } \\
\text { High school and above }\end{array}$ & $\because$ & $\begin{array}{l}0.89(0.73,1.08) \\
0.67(0.52,0.86)\end{array}$ & & & $\begin{array}{l}1.30(1.15,1.48) \\
0.85(0.62,1.16)\end{array}$ & \\
\hline Occupation & & & 0.835 & & & 0.180 \\
\hline $\begin{array}{l}\text { Yes } \\
\text { No }\end{array}$ & $\because$ & $\begin{array}{l}0.87(0.71,1.08) \\
0.84(0.68,1.02)\end{array}$ & & & $1.10(0.69,1.44)$ & \\
\hline Marital status & & $0.04(0.009,1.02)$ & 0.985 & & $1.14(1.00,1.30)$ & 0.546 \\
\hline $\begin{array}{l}\text { Yes } \\
\text { No }\end{array}$ & $\because$ & $\begin{array}{l}0.85(0.73,0.98) \\
0.69(036,132)\end{array}$ & & & $1.06(0.93,1.23)$ & 0.040 \\
\hline Household income, (yuan) & & & 0.048 & & & 0.032 \\
\hline $\begin{array}{l}<20000 \\
220000\end{array}$ & - & $\begin{array}{l}1.04(0.83,1.30) \\
0.74(0.62,0.90)\end{array}$ & & & $\begin{array}{l}1.24(1.06,1.46) \\
0.95(0.80,1.14)\end{array}$ & \\
\hline Alcohol consumption & & & 0.133 & & & 0.199 \\
\hline $\begin{array}{l}\text { Yes } \\
\text { No }\end{array}$ & $\because$ & $\begin{array}{l}0.94(0.76,1.16) \\
0.77(0.63,0.95)\end{array}$ & & - & $\begin{array}{l}0.35(0.10,1.28) \\
1.10(0.98,125)\end{array}$ & \\
\hline Smoking status & & & 0.036 & & & 0.581 \\
\hline $\begin{array}{l}\text { Yes } \\
\text { No }\end{array}$ & & $\begin{array}{l}0.96(0.79,1.16) \\
0.73(0.58,0.91)\end{array}$ & & - & $\begin{array}{l}1.73(0.62,4.79) \\
1.09(0.96,1.24)\end{array}$ & \\
\hline MET, (hr/day) & & & 0.134 & & & 0.594 \\
\hline $\begin{array}{l}\leq 15 \\
>15\end{array}$ & & $\begin{array}{l}0.80(0.67,0.97) \\
0.92(0.73,1.16)\end{array}$ & & $\bullet$ & $\begin{array}{l}1.13(0.99,1.29) \\
1.05(0.80,1.38)\end{array}$ & 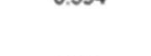 \\
\hline BM1, (kg/m2) & & & 0.365 & & & 0.067 \\
\hline $\begin{array}{l}<24 \\
24.28 \\
228\end{array}$ & & $\begin{array}{l}1.12(0.82,1.52) \\
0.88(0.71,1.08) \\
0.70(0.54,0.92)\end{array}$ & & & $\begin{array}{l}1.12(0.84,1.50) \\
1.00(0.83,1.21) \\
1.20(0.99,1.46)\end{array}$ & \\
\hline $\begin{array}{l}\mathrm{SBP}_{,}(\mathrm{mmHg}) \\
<140\end{array}$ & & $086(0.70,107)$ & 0.657 & & & 0.334 \\
\hline $\begin{array}{l}<140 \\
\geq 140\end{array}$ & & $0.87(0.71,1.07)$ & & & $\begin{array}{l}1.07(0.90,1.26) \\
1.06(0.89,1.25)\end{array}$ & \\
\hline $\begin{array}{l}\text { Random glucose, (mmoll) } \\
<11.1\end{array}$ & & $080(069,094)$ & 0.359 & & 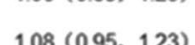 & 0.180 \\
\hline 211.1 & & $1.02(0.62,1.67)$ & & $\rightarrow$ & $0.81(0.55,1.19)$ & \\
\hline Family history of MI & & & 0.385 & & & 0.202 \\
\hline $\begin{array}{l}\text { Yes } \\
\text { No }\end{array}$ & & $0.86(0.74,1.00)$ & & & $\begin{array}{l}1.10(0.63,1.91) \\
1.10(0.97,1.25)\end{array}$ & \\
\hline & & & & & & \\
\hline
\end{tabular}

Subgroup analysis of associations between dairy consumption $\geq 4$ days/week and IHD according to baseline characteristics in males.

Adjusted HRs ( $95 \%$ CIs) dairy consumption by subgroups, age at baseline (years), gender (male or female), education(below high school, high school and above), household income, occupation, marital status(married, live along), and food consumption(eggs, fresh fruit, fresh vegetables, soybean, red meat, poultry), alcohol consumption, smoking status, MET(MET-h), family history of MI.

MET: exercise metabolic equivalent ; MI: myocardial infarction.

The tests for interaction were performed using likelihood ratio tests, which involved comparing models with and without cross-product terms between the baseline stratifying variable and dairy consumption.

Fig. 1 Subgroup analysis of associations between dairy consumption $\geq 4$ days/week and IHD according to baseline characteristics in males. Adjusted HRs ( $95 \% \mathrm{Cls}$ ) dairy consumption by subgroups, age at baseline (years), gender (male or female), education(below high school, high school and above), household income, occupation, marital status(married, live along), and food consumption (eggs, fresh fruit, fresh vegetables, soybean, red meat, poultry), alcohol consumption, smoking status, MET (MET-h), family history of MI. MET: exercise metabolic equivalent; MI: myocardial infarction

In addition, stronger positive associations were also observed among women with age $>50$ y ( $P_{\text {interaction }}$ : $0.929)$, although the interaction test was not statistically significant.

\section{Discussion}

This large-scale prospective study showed that the regular intake of dairy products had a significant protective effect on the onset of IHD in men. However, no similar association was observed among women.

\section{Association between dairy consumption and IHD}

In line with previous studies [22, 23], participants with a higher intake of dairy were more likely to have a lower
BMI and lower blood pressure. Increasing evidence has shown that dairy products are associated with lower blood pressure and arterial stiffness [24].

Dairy products are rich in nutrients [25] (e.g. amino acids, calcium, vitamins), and can be an important nutrient-dense constituent of a healthy diet, an excellent food choice for healthy people of all age groups. Nutrient content and bioactive ingredients in dairy vary greatly, and their impact on health outcomes cannot be characterized fully by the presumed effect of one nutrient as a single biomarker [26]. There are approximately 400 different fatty acids in dairy products, especially in full-fat milk, which is the most complex of all-natural fats [27]. The Chinese Dietary Guideline (2016) recommended that 
adults consume $300 \mathrm{~g}$ of dairy per day (e.g., milk, yogurt) [28]. However, as a country with a high uptake of plant food-based diets and a generally low intake of dairy products, Chinese adults consume few dairy products (e.g., butter, cheese), and the most common type of dairy consumption is liquid milk [29]. It has been reported that China accounted for only $3.5 \%$ of the world's total dairy production, which is much lower than the average of developing countries. The average intake of dairy products was $24.7 \mathrm{~g} / \mathrm{d}$ in 2012 among Chinese adults [30], and that of elderly adults was $32.7 \mathrm{~g} / \mathrm{d}$, which reached a mere $1.21 \%$ of the Chinese dietary guideline recommended level $(300 \mathrm{~g} / \mathrm{d})$. Only $12 \%$ of participants reported the consumption of dairy products in CKB [18].

The Guangzhou Biobank Cohort Study (GBCS) reported that full-fat dairy has a protective association with cardiovascular disease [31]. However, this study was cross-sectional, reverse causation is possible, and it did not adjust for potential confounding by other factors in the diet. Dairy and dairy consumption in Sweden is the highest worldwide. A cohort study in Sweden [7] showed that heptadecanoic acid (17:0) in dairy was associated with a lower risk of IHD, with a relative risk of $0.86(0.78$, 0.96).

The Isfahan Cohort Study (ICS) [32] included 5,432 participants aged $\geq 35$ years who were recruited from January to September 2001. During a median of 10.9 years of follow-up, compared with never consuming dairy, participants with higher dairy intake had an inverse association with IHD, HR (95\% CI) was $0.81(0.65-0.99)$. The Multi-Ethnic Study of Atherosclerosis (MESA) [23], including 5,209 participants aged 45-84 years old at baseline, found that the saturated fatty acids (SFAs) of dairy were associated with a lower IHD risk. In the fully adjusted model, each $5-\mathrm{g} / \mathrm{d}$ increase in consumption was associated with a $21 \%$ lower risk of IHD, HR (95\% CI) was $0.84(0.71-0.99)$. Each 5-unit increase in the percentage of dairy SF was associated with a $38 \%$ lower risk of IHD, HR (95\%CI) was $0.71(0.52-0.98)$, consistent with the findings of the current study.

In the current study, the association was more pronounced in men than in women. A previous meta-analysis reported an inverse association between milk and IHD only in men (RR: 0.93 ; 95\% CI: $0.87,0.99$ ), with a mean milk intake of $313 \mathrm{ml} / \mathrm{d}$ [33], in line with the present study. Furthermore, it has been reported that higher consumption of dairy was related to a lower risk of metabolic syndrome among men [34-36], which might reduce the risk of IHD [37].

In the subgroup analysis of dairy consumption, the relationship between dairy consumption and IHD risk appeared to be more pronounced in men with higher education, household income $\geq 20,000$ yuan, and noncurrent smoking. High socioeconomic status (SES) has been associated with a healthier lifestyle. Participants with a higher SES tend to consume more dairy. Additionally, it has been reported that smoking exacerbates the effects of both total cholesterol (TC) and higher highdensity lipoprotein (HDL) on IHD [38]. Smoking is also an important risk factor for central obesity and is associated with DNA methylation and oxidative stress [39, 40]. Heavy smoking tends to have multiple other healthrelated risk factors, weakening the protection of dairy products.

However, the positive association between dairy consumption and IHD was more pronounced in women with a lower education level (below high school) and household income $<20,000$ yuan. Lower SES was associated with lower levels of milk consumption. With a lower intake of dairy, the association was about the same. The mean age at natural menopause was 48.6 years in CKB [41], and women aged $>50$ years are usually at this stage. The menopausal transition is associated with significant hormonal changes. A previous study reported that women after natural menopause had a higher IHD risk [42]. This may be attributed to the body hormone (e.g., estrogen) levels of women modified after menopause [43], while higher education was associated with a later age at natural menopause [44]. One cross-sectional study [45] reported that estrogen was associated with lower serum cholesterol, lower very-low-density lipoprotein (LDL) cholesterol, and higher high-density lipoprotein (HDL) cholesterol, which may protect women against fatal IHD. In addition, the rate of depression is also higher among women after menopause.

\section{The possible mechanisms underlying the association}

Although the association between dairy consumption and IHD is still controversial, there is existing evidence supporting that dairy products are beneficially associated with IHD. First, higher dairy food consumption was associated with a lower TC [46]. Some types of SFAs in dairy might increase the concentration of HDL-C, which could reverse the cholesterol transport pathways, inhibit LDL-C oxidation, and prevent the inflammatory process [47]. Second, the large amount of calcium in dairy is associated with a lower incidence of hypertension [48], which in turn reduces the risk of IHD. Third, dairy products protect against glucose-induced impairments in vascular function by limiting glucose-induced oxidative stress [49]. In addition, proteins from dairy products promote vascular function by improving nitric oxide bioavailability. Some studies have suggested that full-fat dairy might be a source of bioactive peptides [50,51], which may protect the microvasculature from the detrimental effects of 
sodium. However, more studies are needed to determine the precise mechanisms.

\section{Strengths and limitations of this study}

The present study had several strengths. First, the current study includes a prospective study design and a large number of community-dwelling adults. Second, every participant was followed up for a relatively long time, and detailed information on general health status was collected at baseline, which helped to adjust for a number of potential confounding factors on the relationship between dairy consumption and IHD onset among Chinese adults. A few limitations do need to be considered. The lifestyle was assessed only at baseline, and it might have changed during the long-term follow-up. This study was unable to evaluate long-term trends of dietary patterns and might not necessarily reflect dietary habits over the follow-up. The dietary questionnaire design was relatively simple, collecting consumption data for only some of the major food groups instead of individual food items. Hence, information on dairy product types was not collected. However, it has been reported that the average intake of dairy was $21.8 \mathrm{~kg} / \mathrm{y}$ in Shandong Province, mainly milk (65.7\%) and yogurt (26\%) [52]. In addition, the food frequency was self-reported, which cannot eliminate recall bias.

\section{Conclusion}

In summary, dairy consumption had a protective association with the onset of IHD for men, particularly among men with high-level education and noncurrent smoking. Dairy consumption had a positive association for women who were older and had lower education levels. Therefore, different populations should be given different dietary recommendations for dairy to prevent IHD.

\begin{abstract}
Abbreviations
CKB: China Kadoorie Biobank; IHD: Ischemic heart disease; MCE: Incident major coronary event; HR: Hazard ratio; Cl: Confidence interval; DALYs: Disabilityadjusted life years; WC: Waist circumference; DSPS: Disease surveillance point system; MET: Exercise metabolic equivalent; BMI: Body Mass Index; SBP: Systolic blood pressure; DBP: Diastolic blood pressure; MI: Myocardial infarction; PYS: Pearson years; KoGES: Korean Genome Epidemiology Study Cohort; TC: Total cholesterol; HDL: Higher high-density lipoprotein; SFAs: Saturated fatty acids; GBCS: Guangzhou Biobank Cohort Study; PURE: Prospective Urban Rural Epidemiology Study; ICS: Isfahan Cohort Study; MESA: Multi-Ethnic Study of Atherosclerosis; SES: Socioeconomic status.
\end{abstract}

\section{Supplementary Information}

The online version contains supplementary material available at https://doi. org/10.1186/s12986-022-00645-9.

Additional file 1 Table S1: Baseline characteristics of participants by dairy consumption. Table S2: IHD incident characteristics of participants according to age. Table S3: Risk of MCE and IHD mortality associated with consumption of dairy among 14,908 male and 18,447 female participants..

\section{Acknowledgements}

We thank Chinese Center for Disease Control and Prevention, Chinese Ministry of Health, National Health and Family Planning Commission of China, and provincial Health Administrative Departments. The most important acknowledgment is to the participants in the study and the members of the survey teams in Qingdao, as well as to the project development and management teams based at Beijing and Oxford.

\section{Authors' contributions}

JS, CP and FL collected and analyzed the date, drafted and edited the manuscript. YG, PP, SW, ZP, ZC and LL collected the date. XT, RG designed the study, and reviewed the manuscript. All the authors have read and approved the final manuscript.

\section{Funding}

This work was supported by grants (2016YFC0900500, 2016YFC0900501, 2016YFC0900504) from the National Key Research and Development Program of China, grants from the Kadoorie Charitable Foundation in Hong Kong and grants (088158/Z/09/Z, 104085/Z/14/Z) from Wellcome Trust in the UK. The work also supported by Qingdao Outstanding Health Professional Development Fund.

\section{Availability of data and materials}

Details of how to access China Kadoorie Biobank data and details of the data release schedule are available from www.ckbiobank.org/site/Data+Access.

\section{Declarations}

Ethics approval and consent to participate

The CKB study was approved by the Ethical Review Committee of the Chinese Center for Disease Control and Prevention and the Oxford Tropical Research Ethics Committee, University of Oxford. All participants provided informed written consent prior to participation in the study.

\section{Consent for publication}

Not applicable.

\section{Competing interests}

The authors have declared that no competing interests exist.

\section{Author details}

${ }^{1}$ Department of Nutrition and Food Hygiene, School of Public Health, Qingdao University, Qingdao 266071, China. ${ }^{2}$ Qingdao Municipality Center for Disease Control and Prevention, Qingdao 266033, China. ${ }^{3}$ Qingdao Institute of Preventive Medicine, Qingdao 266033, China. ${ }^{4}$ Chinese Academy of Medical Sciences, Beijing 100730, China. ${ }^{5}$ Clinical Trial Service Unit and Epidemiological Studies Unit (CTSU), Nuffield Department of Population Health, University of Oxford, Oxford, UK. ${ }^{6}$ Department of Epidemiology and Biostatistics, School of Public Health, Peking University Health Science Center, Beijing 100191, China.

Received: 22 October 2021 Accepted: 6 February 2022

Published online: 19 February 2022

\section{References}

1. Chen ZF, Young L, Yu CH, Shiao SPK. A meta-prediction of methylenetetrahydrofolate-reductase polymorphisms and air pollution increased the Risk of Ischemic Heart Diseases Worldwide. Int J Environ Res Public Health. 2018;15:1453.

2. Wang W, Hu M, Liu H, Zhang X, Li H, Zhou F, Liu YM, Lei F, Qin JJ, Zhao YC, et al. Global Burden of Disease Study 2019 suggests that metabolic risk factors are the leading drivers of the burden of ischemic heart disease. Cell Metab. 2021;33:1943-1956.e1942.

3. Ma LY, Chen WW, Gao RL, Liu LS, Zhu ML, Wang YJ, Wu ZS, Li HJ, Gu DF, Yang YJ, et al. China cardiovascular diseases report 2018: an updated summary. J Geriatr Cardiol. 2020;17:1-8.

4. Global burden of 369 diseases and injuries in 204 countries and territories, 1990-2019: a systematic analysis for the Global Burden of Disease Study 2019. Lancet 2020; 396:1204-1222. 
5. Levy M, Chen Y, Clarke R, Bennett D, Tan Y, Guo Y, Bian Z, Lv J, Yu C, Li $L$, et al. Socioeconomic differences in health-care use and outcomes for stroke and ischaemic heart disease in China during 2009-16: a prospective cohort study of 0.5 million adults. Lancet Glob Health. 2020:8:e591-602

6. Harcombe Z. US dietary guidelines: is saturated fat a nutrient of concern? Br J Sports Med. 2019;53:1393-6.

7. Trieu K, Bhat S, Dai Z, Leander K, Gigante B, Qian F, Korat AVA, Sun Q, Pan $X F$, Laguzzi $F$, et al. Biomarkers of dairy fat intake, incident cardiovascular disease, and all-cause mortality: a cohort study, systematic review, and meta-analysis. PLoS Med. 2021;18:e1003763.

8. Fontecha J, Calvo MV, Juarez M, Gil A, Martínez-Vizcaino V. Milk and dairy product consumption and cardiovascular diseases: an overview of systematic reviews and meta-analyses. Adv Nutr. 2019;10:S164-s189.

9. Lovegrove JA, Givens DI. Dairy food products: good or bad for cardiometabolic disease? Nutr Res Rev. 2016;29:249-67.

10. Dehghan M, Mente A, Rangarajan S, Sheridan P, Mohan V, lqbal R, Gupta R, Lear S, Wentzel-Viljoen E, Avezum A, et al. Association of dairy intake with cardiovascular disease and mortality in 21 countries from five continents (PURE): a prospective cohort study. Lancet. 2018;392:2288-97.

11. Guo J, Astrup A, Lovegrove JA, Gijsbers L, Givens DI, Soedamah-Muthu SS. Milk and dairy consumption and risk of cardiovascular diseases and all-cause mortality: dose-response meta-analysis of prospective cohort studies. Eur J Epidemiol. 2017;32:269-87.

12. Astrup A, Bradley BHR, Brenna JT, Delplanque B, Ferry M, Torres-Gonzalez M. Regular-fat dairy and human health: A Synopsis of Symposia Presented in Europe and North America (2014-2015). Nutrients. 2016;8:463.

13. Willett W, Rockström J, Loken B, Springmann M, Lang T, Vermeulen S, Garnett T, Tilman D, DeClerck F, Wood A, et al. Food in the Anthropocene: the EAT-Lancet Commission on healthy diets from sustainable food systems. Lancet. 2019;393:447-92.

14. Lee HA, An H, Lee E. Dietary patterns related to cardiovascular disease based on reduced rank regression analysis of healthy middle-aged Koreans: data from the community-based Korean Genome and Epidemiology Study (KoGES) cohort. Am J Clin Nutr. 2020;111:1159-69.

15. Wang XJ, Jiang CQ, Zhang WS, Zhu F, Jin YL, Woo J, Cheng KK, Lam TH, Xu L. Milk consumption and risk of mortality from all-cause, cardiovascular disease and cancer in older people. Clin Nutr. 2020;39:3442-51.

16. Huang L, Wang Z, Wang $H$, Zhao L, Jiang H, Zhang B, Ding G. Nutrition transition and related health challenges over decades in China. Eur J Clin Nutr. 2021;75:247-52.

17. Chen Z, Lee L, Chen J, Collins R, Wu F, Guo Y, Linksted P, Peto R. Cohort profile: the Kadoorie Study of Chronic Disease in China (KSCDC). Int J Epidemiol. 2005;34:1243-9.

18. Chen Z, Chen J, Collins R, Guo Y, Peto R, Wu F, Li L. China Kadoorie Biobank collaborative g: China Kadoorie Biobank of 0.5 million people: survey methods, baseline characteristics and long-term follow-up. Int J Epidemiol. 2011;40:1652-66.

19. Chen Z, Yang G, Offer A, Zhou M, Smith M, Peto R, Ge H, Yang L, Whitlock G. Body mass index and mortality in China: a 15-year prospective study of 220,000 men. Int J Epidemiol. 2012;41:472-81.

20. Yu C, Shi Z, Lv J, Du H, Qi L, Guo Y, Bian Z, Chang L, Tang X, Jiang Q, et al. Major dietary patterns in relation to general and central obesity among Chinese Adults. Nutrients. 2015;7:5834-49.

21. Yang G, Hu J, Rao KQ, Ma J, Rao C, Lopez AD. Mortality registration and surveillance in China: history, current situation and challenges. Popul Health Metr. 2005;3:3.

22. Panagiotakos DB, Pitsavos CH, Zampelas AD, Chrysohoou CA, Stefanadis Cl. Dairy products consumption is associated with decreased levels of inflammatory markers related to cardiovascular disease in apparently healthy adults: the ATTICA study. J Am Coll Nutr. 2010;29:357-64.

23. de Oliveira Otto MC, Mozaffarian D, Kromhout D, Bertoni AG, Sibley CT, Jacobs DR Jr, Nettleton JA. Dietary intake of saturated fat by food source and incident cardiovascular disease: the Multi-Ethnic Study of Atherosclerosis. Am J Clin Nutr. 2012;96:397-404.

24. Bhavadharini B, Dehghan M, Mente A, Rangarajan S, Sheridan P, Mohan V, lqbal R, Gupta R, Lear S, Wentzel-Viljoen E, et al. Association of dairy consumption with metabolic syndrome, hypertension and diabetes in 147,812 individuals from 21 countries. BMJ Open Diabetes Res Care. 2020;8:e000826.
25. Lovegrove JA, Hobbs DA. New perspectives on dairy and cardiovascular health. Proc Nutr Soc. 2016;75:247-58.

26. Astrup A, Geiker NRW, Magkos F. Effects of full-fat and fermented dairy products on cardiometabolic disease: food is more than the sum of its parts. Adv Nutr (Bethesda, Md). 2019;10:924S-930S.

27. Månsson HL. Fatty acids in bovine milk fat. Food Nutr Res. 2008;52:1821.

28. Yuexin Y, Huanmei Z. Introduction of Dietary Guidelines for Chinese Residents. J Acta Nutrimenta Sinica. 2016;38:209-17.

29. Liu Z, Pang S, Li Y, Man Q, Li L. Zhang J [Consumption status of dairy products in Chinese aged 60 and above in 2010-2012]. Wei Sheng Yan Jiu. 2016;45:708-13.

30. He YN, Yang XG, Xia J, Zhao LY, Yang YX. Consumption of meat and dairy products in China: a review. Proc Nutr Soc. 2016;75:385-91.

31. Sun Y, Jiang C, Cheng KK, Zhang W, Leung GM, Lam TH, Schooling CM. Milk consumption and cardiovascular risk factors in older Chinese: the Guangzhou Biobank Cohort Study. PLoS ONE. 2014;9:e84813.

32. Talaei M, Hosseini N, van Dam RM, Sadeghi M, Oveisgharan S, Dianatkhah M, Sarrafzadegan N. Whole milk consumption and risk of cardiovascular disease and mortality: Isfahan Cohort Study. Eur J Nutr. 2019;58:163-71.

33. Soedamah-Muthu SS, Ding EL, Al-Delaimy WK, Hu FB, Engberink MF, Willett WC, Geleijnse JM. Milk and dairy consumption and incidence of cardiovascular diseases and all-cause mortality: dose-response metaanalysis of prospective cohort studies. Am J Clin Nutr. 2011;93:158-71.

34. Azadbakht L, Mirmiran P, Esmaillzadeh A, Azizi F. Dairy consumption is inversely associated with the prevalence of the metabolic syndrome in Tehranian adults. Am J Clin Nutr. 2005;82:523-30.

35. Fumeron F, Lamri A, Abi Khalil C, Jaziri R, Porchay-Baldérelli I, Lantieri O, Vol S, Balkau B, Marre M. Dairy consumption and the incidence of hyperglycemia and the metabolic syndrome: results from a french prospective study, Data from the Epidemiological Study on the Insulin Resistance Syndrome (DESIR). Diabetes Care. 2011;34:813-7.

36. Khan B, Nowson CA, Daly RM, English DR, Hodge AM, Giles GG, Ebeling PR. Higher dietary calcium intakes are associated with reduced risks of fractures, cardiovascular events, and mortality: A Prospective Cohort Study of Older Men and Women. J Bone Miner Res. 2015;30:1758-66.

37. Drehmer M, Pereira MA, Schmidt MI, Alvim S, Lotufo PA, Luft VC, Duncan BB. Total and full-fat, but not low-fat, dairy product intakes are inversely associated with metabolic syndrome in adults. J Nutr. 2016;146:81-9.

38. Nakamura K, Barzi F, Huxley R, Lam TH, Suh I, Woo J, Kim HC, Feigin VL, Gu D, Woodward M. Does cigarette smoking exacerbate the effect of total cholesterol and high-density lipoprotein cholesterol on the risk of cardiovascular diseases? Heart. 2009;95:909-16.

39. Zhang Y, Florath I, Saum KU, Brenner H. Self-reported smoking, serum cotinine, and blood DNA methylation. Environ Res. 2016;146:395-403.

40. Gao X, Gào X, Zhang Y, Breitling LP, Schöttker B, Brenner H. Associations of self-reported smoking, cotinine levels and epigenetic smoking indicators with oxidative stress among older adults: a population-based study. Eur J Epidemiol. 2017;32:443-56.

41. Yang L, Lin L, Kartsonaki C, Guo Y, Chen Y, Bian Z, Xie K, Jin D, Li L, Lv J, et al: Menopause Characteristics, Total Reproductive Years, and Risk of Cardiovascular Disease Among Chinese Women. Circ Cardiovasc Qual Outcomes 2017; 10

42. Brzostek T, Rak A, Piórecka B, Zwirska J, Nowacka A, Zyznawska B, Schlegel-Zawadzka M. Selected risk factors for coronary heart disease in a group of women aged 30-65 in Kraków. Wiad Lek. 2004;57(Suppl 1):24-8.

43. El Khoudary SR, Shields KJ, Janssen I, Budoff MJ, Everson-Rose SA, Powell LH, Matthews KA: Postmenopausal Women With Greater Paracardial Fat Have More Coronary Artery Calcification Than Premenopausal Women: The Study of Women's Health Across the Nation (SWAN) Cardiovascular Fat Ancillary Study. J Am Heart Assoc 2017; 6.

44. Wang M, Gong WW, Hu RY, Wang H, Guo Y, Bian Z, Lv J, Chen ZM, Li LM, Yu M: Age at natural menopause and associated factors in adult women: Findings from the China Kadoorie Biobank study in Zhejiang rural area. PLoS One 2018; 13:e0195658.

45. Tikkanen MJ, Nikkila EA. Menopausal oestrogen therapy, serum lipoproteins, and ischaemic heart disease. Lancet. 1981;1:1319.

46. Liu Y, Poon S, Seeman E, Hare DL, Bui M, Iuliano S. Fat from dairy foods and "meat" consumed within recommended levels is associated with favourable serum cholesterol levels in institutionalised older adults. J Nutr Sci. 2019;8:e10. 
47. Wang XY, Liu FC, Yang XL, Li JX, Cao J, Lu XF, Huang JF, Li Y, Chen JC, Zhao LC, et al. Association of cardiovascular diseases with milk intake among general Chinese adults. Chin Med J (Engl). 2020;133:1144-54.

48. Shin BR, Choi YK, Kim HN, Song SW. High dietary calcium intake and a lack of dairy consumption are associated with metabolic syndrome in obese males: the Korean National Health and Nutrition Examination Survey 2010 to 2012. Nutr Res. 2016;36:518-25.

49. McDonald JD, Mah E, Dey P, Olmstead BD, Sasaki GY, Villamena FA, Bruno RS. Dairy milk, regardless of fat content, protects against postprandial hyperglycemia-mediated impairments in vascular endothelial function in adults with prediabetes by limiting oxidative stress responses that reduce nitric oxide bioavailability. J Nutr Biochem. 2019;63:129-39.

50. Alba BK, Stanhewicz AE, Dey P, Bruno RS, Kenney WL, Alexander LM. Controlled feeding of an 8-d, high-dairy cheese diet prevents sodiuminduced endothelial dysfunction in the cutaneous microcirculation of healthy, older adults through reductions in superoxide. J Nutr. 2020;150:55-63.

51. Stanhewicz AE, Alba BK, Kenney WL, Alexander LM. Dairy cheese consumption ameliorates single-meal sodium-induced cutaneous microvascular dysfunction by reducing ascorbate-sensitive oxidants in healthy older adults. Br J Nutr. 2016;1 16:658-65.

52. Aihua L, Zhicai Y. 2020 China Statistics Theory and Practice. Beijing: China Statistics Press; 2021.

\section{Publisher's Note}

Springer Nature remains neutral with regard to jurisdictional claims in published maps and institutional affiliations.

- fast, convenient online submission

- thorough peer review by experienced researchers in your field

- rapid publication on acceptance

- support for research data, including large and complex data types

- gold Open Access which fosters wider collaboration and increased citations

- maximum visibility for your research: over $100 \mathrm{M}$ website views per year

At BMC, research is always in progress.

Learn more biomedcentral.com/submissions 